\title{
Comparative Assessment of Clients Satisfaction with Doctors Services in Teaching and Mission Hospitals in South East Nigeria
}

Ofoegbu Cosmas Chiedozie* and Emelumadu Obiageli Fidelia

Department of Community Medicine, Nnamdi Azikiwe University Teaching Hospital, Nnewi, Nigeria

\begin{abstract}
Background: Patients' satisfaction is an individual's positive assessment regarding a variegated aspect of healthcare and the perception about the quality of services offered in that health facility. Patients who are not satisfied with healthcare services in a certain health facility are very likely to stop seeking treatment in that facility.

Objective: To determine satisfaction level of pregnant mothers with the antenatal services provided by the doctors.

Methods: Using an interviewer administered questionnaire, information on clients' satisfaction was obtained from 500 women attending antenatal care clinic through exit interview. Systematic random sampling was used to select anticipants. Data were entered in to the IBM SPSS software, and analyzed. Results were presented as proportions in percentages. $P$ value $<0.05$ at $95 \%$ confidence interval was considered significant.
\end{abstract}

Study design: This was a comparative cross sectional study.

Settings: The study sites were; Nnamdi Azikiwe University Teaching Hospital Nnewi, Anambra State University Teaching Hospital Awka, St Charles Borromeo Specialist Hospital, Onitsha and Regina Ceali Specialist Hospital, Awka all in Anambra state.

Participants: The study population comprised of 500 pregnant women attending antenatal clinics of the teaching and mission hospitals in Anambra state.

Main outcome measures: Patient expectations of quality care, patient satisfaction.

Results: More clients from teaching hospitals (93.4\%) were satisfied with the attention they obtained from the doctors compared with mission hospitals respondents (92\%) though this different was not statistically significant $\left(x^{2}=4.101, P=0.417\right)$. Ninety three percent $(93 \%)$ of the total respondents were satisfied with the attention they obtain from the doctors. Satisfaction with time spent with the doctor and doctor's explanation what the clients want to know was higher among teaching hospitals respondents $(97.7 \%$ and $95.6 \%)$ compared with mission hospitals respondents $(90.7 \%$ and $89.4 \%$ ). However, the differences were not statistically significant. Majority of the respondents from teaching and mission hospitals were satisfied with time spent with the doctors (95.4\%) and doctor's explanation (93.4\%).

Conclusion: Periodic patient satisfaction survey on different sections of the antenatal clinic should be institutionalized to provide feedback for continuous quality improvement.

Keywords: Antenatal care; Perception; Satisfaction; Quality; Teaching hospital; Mission hospital; Anambra state

\section{Introduction}

Satisfaction is the evaluation of clients' on service or products and how it fulfills their needs and expectations [1-3]. Satisfaction with healthcare services is defined as the extent to which the patients seeking treatment experience positive perception of the care provided by the nursing or medical staff [4-6]. Patient satisfaction is defined here in terms of patients' evaluations of what they experienced during their healthcare. It therefore reflects the gap between the expected service and the experience of the service, from the client's point of view. Patients' experiences are their direct, personal observations of their healthcare. Patients' expectations have been defined as the anticipation that given events are likely to occur during, or as an outcome of, healthcare. In this way, what people expect to receive from their healthcare, compared with what they received in practice, are strongly important in influencing patients' evaluations of their care ('satisfaction') [7]. It is often argued that a superfluity of perceived healthcare over anticipated or expected leads to increased satisfaction and in reverse, that unfulfilled expectations lead to increased dissatisfaction [7-9]. Ideally, patients who are satisfied with the care provided by the healthcare staff, are more likely to utilize health services in future and comply with the prescribed medical treatment to completion $[8,9]$. For patients to be more satisfied with treatment there is need to provide high quality healthcare which is viewed as safe, timely, effective, efficient, equitable, and patientcentered [10].

Measuring client or patient satisfaction has become an integral part of hospital/clinic management strategies across the globe. Moreover, the quality assurance and accreditation process in most countries requires that the satisfaction of clients be measured on a regular basis [10]. Asking patients what they think about the care and treatment they have received is an important step towards improving the quality of care, and ensure local health services are meeting patients' needs [11-15].

*Corresponding author: Ofoegbu Cosmas Chiedozie, Department of Community Medicine, Nnamdi Azikiwe University Teaching Hospital, Nnewi, Nigeria, Tel: +2438037417782; E-mail: cosmasofoegbu@yahoo.co.uk

Received November 19, 2018; Accepted November 24, 2018; Published December 01, 2018

Citation: Chiedozie OC, Fidelia EO (2018) Comparative Assessment of Clients Satisfaction with Doctors Services in Teaching and Mission Hospitals in South East Nigeria. J Health Educ Res Dev 6: 288. doi: 10.4172/2380-5439.1000288

Copyright: (๑) 2018 Chiedozie OC, et al. This is an open-access article distributed under the terms of the Creative Commons Attribution License, which permits unrestricted use, distribution, and reproduction in any medium, provided the original author and source are credited. 
It is an established fact that satisfaction influences whether a person seeks medical advice, complies with treatment and maintains a continuing relationship with practitioners. It has been emphasized by Donabadian, a leading theorist in the field of quality assurance that Client satisfaction is of fundamental importance as a measure of the quality of care because it gives information on the provider's success at meeting those client values and expectations, which are matters on which the client is the ultimate authority [10]. This study would have an important input in assessing the level of clients' satisfaction with antenatal services/care provided by doctors in teaching and mission hospitals, identify the factors affecting the clients' satisfaction, and provide a recommendation on an improved antenatal service delivery that will be helpful to fill research knowledge gaps which ultimately contributes to enhance quality of antenatal services in the hospital, reduce mortality and morbidity rate, and improve the level of clients' satisfaction.

\section{Methods}

\section{Study design}

This was a comparative cross sectional study on clients' satisfaction with antenatal care services offered by doctors in anambra state: comparison of teaching and mission hospitals.

\section{Sample size and selection}

The minimum sample size for this study was based on $5 \%$ significance level and a power of $80 \%$.

Formula:

$$
n=\frac{\left[2(z \alpha+z \beta)^{2} p(1-p)\right]^{16}}{d^{2}}
$$

Where, $\mathrm{n}=$ sample size for individual group, $\mathrm{Z} \alpha=$ standard normal deviate $=1.96$ at $95 \%$ confidence interval, $Z \beta=$ statistical power at $80 \%=0.8$ [16].

$\mathrm{p}=$ arithmetic average of two proportions which is $(P 1+P 2) / 2$

$\mathrm{p} 1=$ proportion of clients satisfied with antenatal care in a federal teaching hospital=0.943 [17].

p2=proportion of clients satisfied with antenatal care in first level health facilities $=0.814$ [18].

\section{$\mathrm{P}=(0.943+0.814) / 2=0.87855$}

$\mathrm{d}=$ arithmetic difference between the two population=P2-P1

$\mathrm{d}=0.943-0.814=0.129$

$\mathrm{d}^{2}=0.016641$

$\mathrm{Z} \alpha=1.96$

$\mathrm{Z} \beta=0.8$

$\mathrm{P}=0.8785$

Substituting into the formula:

$\mathrm{n}=[2(z \alpha+z \beta) P(1-p)] / d^{2}$

$\mathrm{n}=[2(1.96+0.8) 20.8785(1-0.8785)] / 0.016641$

$\mathrm{n}=97.72$

$\mathrm{n}=98$.
Using an anticipated non response rate of $10 \%(10 \times 98 / 100)=9.8$.

Therefore $98+9.8=107.8$ which are approximately 108 persons?

The minimum sample size for one of the health facilities was 108 pregnant women.

The minimum sample size for the study was 216 .

In order to increase the power of the study, avoid cluster effect and increase study external validity, the sample size used was 500 pregnant women. The respondents chosen from each facility were determined using a proportionate allocation by size of the facility.

\section{The clinic patient surveys}

The study sites included two teaching hospitals (Nnamdi Azikiwe University teaching hospital Nnewi and Anambra state University teaching hospital, Awka) and two mission hospitals (St. Charles Borromeo hospital Onitsha and Regina Caeli Hospital Awka).

\section{The population patient surveys}

The study population comprised 500 pregnant women attending antenatal clinics of teaching and mission hospitals in Anambra state.

\section{The questionnaires}

Data was collected using a pre-tested semi-structured interviewer administered questionnaire. The questionnaire was designed by the United States Departments of Health and Human Services, for patient satisfaction surveys, adapted and modified for this study [19]. Exit interview was conducted and participants were selected using a systematic random sampling with a sampling interval of two until sample size is achieved. Participants who declined consent were excluded. Also those on booking antenatal visit or have not attended previously in index pregnancy were excluded.

\section{Results}

The socio-demographic characteristics of respondents in teaching and mission hospitals are shown in Tables 1-3. Data was obtained from 500 respondents, consisting of three hundred and twenty one teaching hospital clients and one hundred and seventy nine mission hospital clients. The mean ages of the teaching hospital respondents was 29.6 \pm 4.0 and is slightly higher compared with that of mission hospitals respondents which was $29.5 \pm 4.6$. All the respondents from Mission hospitals were all currently married compared to the respondents from teaching hospitals where $2 \%$ of the respondents were never married. All the respondents had formal education, but a higher proportion of the mission hospitals respondents, (40\%) had Bachelor degree/ HND as the highest educational qualification attained compared with the teaching hospitals respondents where Senior Secondary/ Grade II Teaching Certificate was the highest educational qualification obtained by majority of the respondents (51.1\%). However, this is not statistically significant. There is a statistically significant difference in the denomination of the respondents, $(\mathrm{P}=0.004)$ as the percentage of respondents were higher in mission hospitals (81.3\%) compared to teaching hospitals (55.5\%). Also, the percentage of Pentecostal respondents was higher in teaching hospitals (15.6\%) than in mission hospitals (2.7\%). A higher proportion of respondents from both populations were Igbo ethnicity $(95.8 \%)$ with the rest being Yoruba (1.8\%), Hausa $(0.4 \%)$, Igala or Efik $(2.0 \%)$. The highest proportion of the respondents from teaching hospitals are civil servants $(33.4 \%)$ followed by business owners (33.2\%), compared to the respondents from mission hospitals where the highest proportion of respondents were students (26.7\%) followed by unemployed women (25.3\%). 
Citation: Chiedozie OC, Fidelia EO (2018) Comparative Assessment of Clients Satisfaction with Doctors Services in Teaching and Mission Hospitals in South East Nigeria. J Health Educ Res Dev 6: 288. doi: 10.4172/2380-5439.1000288

Page 3 of 6

Result revealed that more clients from teaching hospitals (93.4\%) were satisfied with the attention they obtained from the doctors compared with mission hospitals respondents (92\%) though this different was not statistically significant $\left(\chi^{2}=4.101, \mathrm{P}=0.417\right)$. Ninety three per cent of the total respondents were satisfied with the attention they obtain from the doctors, (44.8\% were strongly satisfied, $43.4 \%$ were satisfied and $4.8 \%$ were somewhat satisfied).

Satisfaction with time spent with the doctor and doctor's explanation what the clients want to know was higher among teaching hospitals respondents $(97.7 \%$ and $95.6 \%)$ compared with mission hospitals respondents $(90.7 \%$ and $89.4 \%)$. However, the differences were not statistically significant. Majority of the respondents from teaching and mission hospitals were satisfied with time spent with the doctors (95.4\%) and doctor's explanation (93.4\%).

Association of age, educational level, denomination and occupation of respondents with clients' satisfaction with doctor's explanation of what they want to know. Occupation showed a significant association with this variable, $\left(\chi^{2}=24.141, \mathrm{P}=0.040\right)$.

\section{Qualitative findings}

Focus group discussion: There is a high rate of satisfaction with doctors' services among respondents in both teaching and mission hospitals. This is depicted below:

"I think the services of the doctors are very good" (Response 1, Teaching Hospital).
"What I like best about this hospital is the Doctor's services" (Response 2, Teaching Hospital).

"The hospital has qualified doctors" (Response 3, Teaching Hospital).

"I like the services of the doctors" (Response 4, Teaching Hospital).

"What I like best is how seriously the doctors are" (Response 5, Teaching Hospital).

"I like the attention I get from the doctors" (Response 6, Teaching Hospital).

"There should be improvement in the services and attitudes of the workers apart from doctors" (Response 7, Teaching Hospital)

"What I like best in this hospital is the doctor-patient relationship", (Response 1, Mission Hospital).

"The hospital has qualified doctors" (Response 2, Mission Hospital).

"I like my doctor's attention and the way the doctors attend to their patient" (Response 3, Mission Hospital).

"I like Dr. Muoghalu's attention to the patients" (Response 4, Mission Hospital).

"I like/the expertise and experiences of their doctors and accessibility of medical equipment's” (Response 5, Mission Hospital).

"As you can see in my view of point, the doctors are good at their work" (Response 6, Mission Hospital).

\begin{tabular}{|c|c|c|c|c|c|}
\hline Variables & Teaching Hospital (n=321) n (\%) & Mission Hospital (n=179) n (\%) & Total $(n=500) n(\%)$ & Test Statistic $\mathrm{X}^{2}$ & P-value \\
\hline & & Age (years) & & & \\
\hline $15-24$ & $0(0.0)$ & $2(1.1)$ & $2(0.4)$ & \multirow{5}{*}{$t=0.152$} & \multirow{5}{*}{0.879} \\
\hline $25-34$ & $278(86.6)$ & $146(81.6)$ & $424(84.8)$ & & \\
\hline Above 35 & $43(13.4)$ & $31(17.3)$ & $74(14.8)$ & & \\
\hline Mean age & 29.6 & 29.5 & & & \\
\hline Standard deviation & 4 & 4.6 & & & \\
\hline \multicolumn{6}{|c|}{ Marital status } \\
\hline Never married & $6(2.0)$ & $0(-)$ & $6(1.2)$ & Fishers Exact & \multirow{2}{*}{0.132} \\
\hline Currently married & $315(98.0)$ & $179(100.0)$ & $494(98.8)$ & 9.021 & \\
\hline \multicolumn{6}{|c|}{ Educational level } \\
\hline \multicolumn{6}{|c|}{ No formal education } \\
\hline O’level & $178(55.5)$ & $60(33 \%)$ & $3(0.6)$ & \multirow{4}{*}{8.223} & \multirow{4}{*}{0.144} \\
\hline OND, NCE/Technical education & $57(17.8)$ & $38(21.3)$ & $95(19)$ & & \\
\hline Bachelor, HND & $72(22.2)$ & $72(40.0)$ & $144(28.8)$ & & \\
\hline PhD, Masters & $14(4.4)$ & $9(5.3)$ & $23(4.6)$ & & \\
\hline \multicolumn{6}{|c|}{ Denomination/Denomination } \\
\hline Christianity & & & & Fishers Exact & \\
\hline Catholic & $178(55.6)$ & $145(81.3)$ & $323(64.6)$ & 11.08 & $0.004^{* *}$ \\
\hline Anglican & $93(28.9)$ & $29(16.0)$ & $122(24.4)$ & & \\
\hline Pentecost & $50(15.6)$ & $5(2.7)$ & $55(11.0)$ & & \\
\hline Tribe & & & & Fishers Exact & \\
\hline Igbo & $307(95.6 \%)$ & 172(96.3) & 179)95.8) & \multirow{4}{*}{1.698} & \multirow{4}{*}{0.428} \\
\hline Yoruba & $6(1.8)$ & $3(1.7)$ & $9(1.8)$ & & \\
\hline Hausa & $0(-)$ & $2(1.0)$ & $2(0.4)$ & & \\
\hline Others [Igala, Efik] & $8(2.6)$ & $2(1.0)$ & $10(2.0)$ & & \\
\hline \multicolumn{6}{|c|}{ Occupation } \\
\hline Civil servant & $107(33.4)$ & $43(24.0)$ & $150(30.0)$ & \multirow{5}{*}{11.891} & \multirow{5}{*}{$0.018^{*}$} \\
\hline Business owner & $106(33.2)$ & $24(13.3)$ & $130(26.0)$ & & \\
\hline Self employed & $29(8.9)$ & $19(10.7)$ & $48(9.6)$ & & \\
\hline Student & $50(15.6)$ & $48(26.7)$ & $98(19.6)$ & & \\
\hline Unemployed & $29(8.9)$ & $45(25.3)$ & $74(14.8)$ & & \\
\hline
\end{tabular}

Table 1: Socio-Demographic Characteristics of Respondent in Teaching and Mission Hospital Antenatal Clinics in Anambra State. 
Citation: Chiedozie OC, Fidelia EO (2018) Comparative Assessment of Clients Satisfaction with Doctors Services in Teaching and Mission Hospitals in South East Nigeria. J Health Educ Res Dev 6: 288. doi: 10.4172/2380-5439.1000288

Page 4 of 6

\begin{tabular}{|c|c|c|c|c|c|}
\hline Variables & Teaching Hospital (n=321) n (\%) & Mission Hospital $(n=179) n(\%)$ & Total $(n=500) n(\%)$ & $\begin{array}{c}\text { Test Statistic } \\
\mathrm{X}^{2}\end{array}$ & P-value \\
\hline \multicolumn{6}{|c|}{ Age (years) } \\
\hline $15-24$ & $0(0.0)$ & $2(1.1)$ & $2(0.4)$ & \multirow{5}{*}{$t=0.152$} & \multirow{5}{*}{0.879} \\
\hline $25-34$ & $278(86.6)$ & $146(81.6)$ & $424(84.8)$ & & \\
\hline Above 35 & $43(13.4)$ & $31(17.3)$ & $74(14.8)$ & & \\
\hline Mean age & 29.6 & 29.5 & & & \\
\hline Standard deviation & 4 & 4.6 & & & \\
\hline \multicolumn{6}{|c|}{ Marital status } \\
\hline Never married & $6(2.0)$ & $0(-)$ & $6(1.2)$ & Fishers Exact & \multirow{2}{*}{0.132} \\
\hline Currently married & $315(98.0)$ & $179(100.0)$ & 494(98.8) & 9.021 & \\
\hline \multicolumn{6}{|c|}{ Educational level } \\
\hline \multicolumn{6}{|c|}{ No formal education } \\
\hline O'level & $178(55.5)$ & $60(33 \%)$ & $3(0.6)$ & \multirow{4}{*}{8.223} & \multirow{4}{*}{0.144} \\
\hline OND, NCE/Technical education & $57(17.8)$ & $38(21.3)$ & $95(19)$ & & \\
\hline Bachelor, HND & $72(22.2)$ & $72(40.0)$ & $144(28.8)$ & & \\
\hline PhD, Masters & $14(4.4)$ & $9(5.3)$ & $23(4.6)$ & & \\
\hline \multicolumn{6}{|c|}{ Denomination/Denomination } \\
\hline Christianity & & & & Fishers Exact & \\
\hline Catholic & $178(55.6)$ & $145(81.3)$ & $323(64.6)$ & 11.08 & $0.004^{* *}$ \\
\hline Anglican & $93(28.9)$ & $29(16.0)$ & $122(24.4)$ & & \\
\hline Pentecost & $50(15.6)$ & $5(2.7)$ & $55(11.0)$ & & \\
\hline Tribe & & & & Fishers Exact & \\
\hline Igbo & $307(95.6 \%)$ & $172(96.3)$ & 179)95.8) & \multirow{4}{*}{1.698} & \multirow{4}{*}{0.428} \\
\hline Yoruba & $6(1.8)$ & $3(1.7)$ & $9(1.8)$ & & \\
\hline Hausa & $0(-)$ & $2(1.0)$ & $2(0.4)$ & & \\
\hline Others [Igala, Efik] & $8(2.6)$ & $2(1.0)$ & $10(2.0)$ & & \\
\hline \multicolumn{6}{|c|}{ Occupation } \\
\hline Civil servant & $107(33.4)$ & $43(24.0)$ & $150(30.0)$ & \multirow{5}{*}{11.891} & \multirow{5}{*}{$0.018^{*}$} \\
\hline Business owner & 106(33.2) & $24(13.3)$ & $130(26.0)$ & & \\
\hline Self employed & $29(8.9)$ & $19(10.7)$ & $48(9.6)$ & & \\
\hline Student & $50(15.6)$ & $48(26.7)$ & $98(19.6)$ & & \\
\hline Unemployed & $29(8.9)$ & $45(25.3)$ & $74(14.8)$ & & \\
\hline
\end{tabular}

Table 2: Clients' Perception of Satisfaction with Doctors' Services in Teaching and Mission Hospital Antenatal Clinics in Anambra State.

\begin{tabular}{|c|c|c|c|c|}
\hline Variables & Satisfied N (\%) & Unsatisfied N (\%) & Test Statistic & P-value \\
\hline \multicolumn{5}{|c|}{ Age in categories } \\
\hline $15-24$ & $107(89.2)$ & $13(50.8)$ & \multirow{3}{*}{10.331} & \multirow{3}{*}{0.587} \\
\hline $25-34$ & 283(94.1) & $18(5.9)$ & & \\
\hline$>34$ & $86(91.9)$ & $6(8.1)$ & & \\
\hline \multicolumn{5}{|c|}{ Educational level } \\
\hline O level & 199(90.9) & $20(9.3)$ & \multirow{4}{*}{13.494} & \multirow{4}{*}{0.855} \\
\hline OND/NCE/ Technical & $88(90.7)$ & $9(9.3)$ & & \\
\hline Bachelor/HND & 149(93.1) & $11(6.9)$ & & \\
\hline PHD/Masters & $22(91.7)$ & $2(8.3)$ & & \\
\hline \multicolumn{5}{|c|}{ Denomination } \\
\hline Catholic & $310(90.9)$ & $31(9.1)$ & \multirow{3}{*}{3.642} & \multirow{3}{*}{0.888} \\
\hline Anglican & $107(93.9)$ & $7(6.1)$ & & \\
\hline Pentecostal & $41(91.1)$ & $4(8.9)$ & & \\
\hline \multicolumn{5}{|c|}{ Occupation } \\
\hline Civil servant & $132(91.0)$ & $13(8.9)$ & \multirow{5}{*}{24.141} & \multirow{5}{*}{$0.040^{*}$} \\
\hline Business owner & $114(89.8)$ & $13(10.2)$ & & \\
\hline Self-employed & $46(90.2)$ & $5(9.8)$ & & \\
\hline Student & $96(92.3)$ & $8(7.7)$ & & \\
\hline Unemployed & $77(91.7)$ & $7(8.3)$ & & \\
\hline
\end{tabular}

* $=$ Chi-square test Statistically Significant

Table 3: Influence of Sociodemographic Variables on Perceived Doctor's Explanation of What You Want to Know in Teaching and Mission Hospital Antenatal Clinics in Anambra State. 
"The way the doctors attend to me is not bad" (Response 7, Mission Hospital).

"The doctors here are friendly and I must appreciate the services of doctor Osita" (Response 8, Mission Hospital).

The aspects of doctors' services dissatisfactory to clients in the teaching hospital are:

"Extended length of stay with the doctors when teaching medical students, If you are unlucky to see a doctor when teaching the students, you will have to stay for a very long time" (Response 1, Teaching Hospital).

"Lack of empathy from the very young doctors" (Response 2, Teaching Hospital).

"The doctors should stop using us to do practical for students even when the patient situation is critical it has destroyed many souls" (Response 3, Teaching Hospital).

Participants in teaching hospital are of the opinion that doctors pay more attention to antenatal pregnant women and during child birth but neglect them after delivery.

\section{Discussion}

Clients' satisfaction with doctors' services during antenatal visit was measured using four key points; Attention obtained from the doctor, Time spent with the doctor, Doctor's explanation of what you need to know and Advice/Treatment received from the doctor. Our result showed that $93 \%$ of the respondents were satisfied with the attention obtained from the doctor with $93.4 \%$ respondents from the teaching hospitals and $92 \%$ from the mission hospitals. We further explored the level of satisfaction as strongly satisfied, satisfied and somewhat satisfied, and the results obtained were $44.8 \%, 43.4 \%$ and $4.8 \%$ respectively. On time spent with doctor, $95.4 \%$ were satisfied $(97.7 \%$ from the teaching hospitals and $90.7 \%$ from the mission hospitals) while $35.4 \%, 57.2 \%, 2.8 \%$ were strongly satisfied, satisfied and somewhat satisfied respectively. Satisfaction with doctors' explanation of what clients need to know was high as shown by $93 \%$ of the respondents, though lower response was gotten from the mission hospitals $(95.6 \%$ from the teaching hospitals and $89.4 \%$ from the mission hospitals) while $33.8 \%, 54 \%, 5.2 \%$ were strongly satisfied, satisfied and somewhat satisfied respectively. High level of satisfaction (95.6\%; 95.4\% from teaching hospitals and $96 \%$ from mission hospitals)was also recorded on advice/treatment received from doctor while $33.8 \%, 54 \%, 5.2 \%$ were strongly satisfied, satisfied and somewhat satisfied respectively. Comparing the results of this study to that obtained from a study done in Ekiti state 20, Nigeria where $90 \%$ of the respondents were satisfied with doctor-patient relationship, it can be inferred that there is a high level of satisfaction with care received from the doctors during antenatal services although the research in Ekiti state only looked at the doctor-patient relationship which is an aspect of doctors services, one can begin to assume that there is a little agreement between the findings of that research and the findings in this research. This is because in both studies other aspects of services were assessed and aspects relating to doctors services recorded highest satisfaction for clients. Also the Ekiti study did not explore the satisfaction level as done by this study.

One will begin to assume that maybe working in a religious environment may lead to better commitment or that clients in such environment are likely to rate services higher than others. The doctors in the mission hospitals see more patients per person yet the doctorpatient relationship was still higher than that in teaching hospitals.
This doctor-patient relationship was also noted during the focus group discussion as mission hospital participants knew their doctors by name and referred to them by their names unlike the teaching hospital participants. It can be inferred from here that not necessarily the number of staffs but commitment of the staffs that influences patient satisfaction to services. This is because whereas the teaching hospital antenatal clinics are manned by 18 consultants, over 60 medical officers/resident doctors and numerous house officers the mission hospital antenatal clinics only has 3 consultants and 3 medical officers yet clients were better satisfied with the doctors services. The high satisfaction with doctors' services in the mission hospital is a strong factor that maybe responsible for their huge patronage.

This study revealed that occupation had a significant association with clients' satisfaction with antenatal services given by the doctors $\left(\chi^{2}=24.141, \mathrm{P}=0.040\right)$. This is contrary to the result obtained by Oladapo and Osiberu where they found that socio-demographic and obstetric characteristics were not associated with the overall satisfaction with antenatal care quality [20,21]. Similar finding was also recorded in a study carried out by Nwaeze et al., where the respondents sociodemographic characteristic had limited impact on their perception of antenatal care $(\mathrm{P}>0.005)$ [22]. This difference could be attributed to locations of study areas as our study was carried out in south eastern part of Nigeria while the two studies mentioned were done in south western Nigeria.

\section{Conclusions}

Satisfaction with doctors' care during antenatal services is high in Anambra state, yet not at the optimal level and the problem of dissatisfaction still needs to be tackled objectively. More level of satisfaction was expressed by the respondents of mission hospitals than teaching hospitals as seen in the qualitative findings. The major reason for dissatisfaction with services in the teaching hospital was the use of student doctors in rendering antenatal services.

\section{References}

1. Westaway MS, Rheeder P, Vanzyl DG, Seager JR (2003) Interpersonal and organizational dimensions of patient satisfaction. Journal for Quality in Healthcare 15: 337-344.

2. Inegbenebor AU (2006) Elements of service operations. 1st edn. The Fundamentals of Entrepreneurship, Lagos, Malthouse Press, pp: 164-174.

3. Mathew S, Beth E (2001) Guide to Assessing Client Satisfaction. Health system Trust, Durban, South Africa. Report Number, p: 63.

4. Aldana JM, Piechulek H, Al-Sabir A (2001) Client satisfaction and quality of health care in rural Bangladesh. Bulletin of the World Health Organization 79 : 512-517.

5. Assefa F, Mosse A (2011) Assessment of Clients' satisfaction with health service deliveries at Jimma University specialized hospital. Ethiopian Journal of Health Sciences 21: 101-110.

6. Chirdan O, Lar L, Afolaranmi T, Inalegwu E, Igoh C (2013) Client satisfaction with maternal health services comparism between public and private hospitals in Jos Nigeria. Jos Journal of Medicine 7: 1-9.

7. Bowling A, Rowe G, Lambert N (2012) The measurement of patients expectations for health care. Health Technol Assessment.

8. Health Care Commission (2005) North West London Hospitals. NHS Trust Outpatient Survey Report, 2004/2005.

9. Westaway MS, Rheeder P, van Zyl DG, Seager JR (2003) Interpersonal and organizational dimensions of patient satisfaction: the moderating effects of health status. International Journal for Quality in Health Care 15: 337-344.

10. Donabedian A (1988) The Quality of Care, How can it be assessed?. JAMA 260: $1743-1748$

11. Karkee R, Lee AH, Pokharel PK (2014) Women's perception of quality of 
Citation: Chiedozie OC, Fidelia EO (2018) Comparative Assessment of Clients Satisfaction with Doctors Services in Teaching and Mission Hospitals in South East Nigeria. J Health Educ Res Dev 6: 288. doi: 10.4172/2380-5439.1000288

Page 6 of 6

maternity services: a longitudinal survey in Nepal. BMC Pregnancy and Childbirth 14: 45

12. Pelletier B (2008) Essential resources for the Health Care Quality Professional. 2nd edn. Glenview Report Number, USA.

13. Weisman E, Koch J (1989) Progress notes: Special patient satisfaction issue. Quality Review Bulletin 15: 166-167.

14. lacobucci D, Ostron A, Grayson K (1995) Distinguishing service quality and clients satisfaction: The voice of the consumer. Journal of Consumer Psychology 4: 277-303.

15. Ware JE, Davies-Avery A, Stewart AL (2008) The measurement and meaning of patient satisfaction. Health and Medical Care 1: 3-15.

16. Onwasigwe C (2004) Principles and methods of epidemiology. Demark Publishers, Uwani Enugu, 2nd edn., pp: 123-157.

17. Uzochukwu BS, Onwujekwe OE, Akpala CO (2004) Community Satisfaction with the Quality of Maternal and Child Health Services in South East, Nigeria. East African Medical Journal 81: 293-299.

18. Oladapo OT, Iyaniwura CA, Sule-odu AO (2008) Quality of antenatal services at the primary care level in Southwest Nigeria. African Journal of Reproductive Health 12: 71-92.

19. United States Department of Health and Human Services (2013) Patient Satisfaction Survey Form (Accessed 10/07/2013).

20. Oluwadere CT (2013) Client's Perception of Quality Hospital Services in Ekiti state, Nigeria. Global Research Journal of Medical Sciences 2: 43-47.

21. Oladapo OT (2008) Quality of antenatal services at the primary care level in Southwest Nigeria. Afr J Reprod Health 12: 71-92.

22. Nwaeze IL, Enabor OO, Oluwasola TA, Aimakhu CO (2013) Perception and satisfaction with quality of antenatal care services among pregnant women at the university college hospital, Ibadan, Nigeria. Ann lb Postgrad Med 11: 22-28. 